\title{
STRATEGIC CONSIDERATIONS IN INVENTION AND INNOVATION: THE CASE OF NATURAL RESOURCES
}

\section{By Partha Dasgupta, Richard Gilbert, and Joseph Stiglitz ${ }^{1}$}

\begin{abstract}
Strategic considerations may induce a resource importing country to invent a substitute earlier than it intends to put it to use. There are also circumstances in which it would wish to delay an invention date even if it could obtain it at an earlier date at no extra cost. Similar paradoxical results obtain if resource cartels behave strategically. Setting prices high may be a way of deterring invention. If those engaged in $R \& D$ are not resource users, and the cartel has access to similar R\&D technology, it will pre-empt rivals. This may not be the case if resource users can also engage in $R \& D$.
\end{abstract}

\section{INTRODUCTION}

Cost BENEFrT STUDIES of research and development (R\&D) programs for alternative energy sources (e.g., National Research Council [6]) typically ignore strategic considerations, in particular the fact that the choice of an R\&D program influences the decisions of resource owners, and thereby the current energy market. In this article we present a framework for analyzing such interactions.

Towards this we consider the simplest of technological environments. We suppose that there is a single-grade of an exhaustible natural resource and a potential manufacturing process (a "backstop" technology) which, if developed, will enable a perfect substitute to be produced at constant unit cost. To have an interesting problem we suppose, as is realistic, that unit extraction cost is less than the unit cost of production with the new technology once development has been completed. We suppose further that the entire resource stock has been cartelized, and that the cartel's market is restricted to a single consumer which we shall refer to as the importing country. We ignore uncertainty entirely, so that we may highlight strategic interactions. In particular, we model the $R \& D$ technology as a deterministic function relating capitalized expenditure at the initial date to the date development is completed-the latter date being nearer, the larger is capitalized expenditure. ${ }^{2}$

In the next section we shall analyze optimal R\&D programs for the importing country. For simplicity of exposition we shall suppose there that the importing country's government faces no rivals in R\&D, and that it makes the first move; in doing so it takes into account the cartel's response to its R \& D strategy. Quite clearly, the nature of the intertemporal equilibria depends on which agents have access to the R\&D technology, what is the order of moves, and what kinds of

'In preparing this article we have benefited greatly from the comments of Nancy Gallini and the Editors and from financial support from the National Science Foundation. Gallini et al. [3] have independently developed an analysis simila to the one presented in Section 2.

${ }^{2}$ This is often called a "time-cost" curve in the R \& D literature. See, e.g., Mansfield et al. [5]. 
commitments it is possible to undertake. In Section 3, therefore, we comment briefly on the implications of alternative assumptions regarding this.

\section{R\&D STRATEGY FOR AN IMPORTING COUNTRY}

\subsection{The Model}

The model is partial equilibrium. A foreign cartel is assumed to own the entire stock of an exhaustible natural resource, which is costless to extract. Remaining reserves at date $t(\geq 0)$ are denoted by $S_{t}$, and it is supposed that the initial stock, $S_{0}$, is known. The importing country is the sole demander of the resource and the market demand in this country at each date for the flow of the resource is given by the continuously differentiable function $Q=f(p) \geq 0$, where $p$ denotes the resource price. It is assumed that $f^{\prime}(p)<0$, and we write $p(Q) \equiv f^{-1}(Q)$. We suppose, for expositional ease, that the elasticity of demand is a nonincreasing function of output. Write $R(Q)=Q P(Q)$ as the revenue function and $m(Q)$ $\equiv R^{\prime}(Q)$ for marginal revenue. In what follows we suppose that $R(Q)$ is strictly concave in $Q$. The social rate of discount in the importing country is taken to be a positive number, $r$. For simplicity of exposition we take it that the cartel uses $r$ in discounting its profits (rents).

We shall suppose that the government of the importing country finances its $\mathrm{R} \& \mathrm{D}$ expenditure through general taxation. Once development is completed the backstop technology will enable a perfect substitute to be produced at unit cost $C(>0)$. We assume that $p(0)>C$. We also assume that the government will not be engaged in production, but will make the new technology publicly available. Thus, the sector producing the substitute will be perfectly competitive.

We turn finally to the R\&D technology. Assume that there is a monotonically decreasing and continuously differentiable function $X(T)$, with $X(T)>0$ for all $T \geq 0$, which has the interpretation that completion of $\mathrm{R} \& \mathrm{D}$ at date $T$ requires a commitment of capitalized expenditure $X(T)$ at date $t=0 .{ }^{3}$ For expositional simplicity assume $X(0)=\infty$ and $X(\infty)=0$.

The importing nation's payoff is the present discounted value of the flow of its net social surplus. The government makes the first move by announcing the date development will be completed. By hypothesis the announcement is credible because it is backed by $R \& D$ commitment. The cartel makes the second move by announcing its extraction policy. The cartel's payoff is the present discounted value of the flow of profits. The importing nation behaves stategically by taking the cartel's response into account when choosing its R\&D policy. Let $U(Q)$ $=\int_{0}^{\infty} p\left(Q^{\prime}\right) d Q^{\prime}$, and let $Y$, denote output of the substitute at $t$. It follows that

${ }^{3}$ This is the simplest possible characterization of an R\&D technology. (See Dasgupta and Stiglitz [1] for this and some generalizations.) It implicitly supposes that $T$ is a deterministic functional of the time path of the flow of R\&D expenditures $x_{i}$ (for $0 \leq t \leq T$ ), say $T=F(\{x\}$,$) . Then we may define$ $X(T)$ as:

$$
X(T)=\min _{\left\{x_{i}\right\}} \int_{0}^{T} e^{-n_{1}} x_{t} d t, \quad \text { subject to } T \geq F\left(\left\{x_{t}\right\}\right)
$$


equilibrium of this two-move game can be obtained by solving the following constrained optimization problem:

$$
\begin{aligned}
\underset{T, Y_{t} \geq 0}{\operatorname{maximize}}[ & \int_{0}^{T} U\left(\tilde{Q}_{t}(T)\right) e^{-r t} d t \\
& \left.+\int_{T}^{\infty}\left[U\left(\tilde{Q}_{l}(T)+Y_{t}\right)-C Y_{t}\right] e^{-r t} d t-X(T)-\pi\right]
\end{aligned}
$$

(1) where $\tilde{Q}_{1}(T)$ maximizes

$$
\begin{aligned}
& \int_{0}^{T} R\left(Q_{t}\right) e^{-r t} d t+\int_{T}^{\infty} \min \left\{R\left(Q_{t}\right), C Q_{t}\right\} e^{-r t} d t=\pi \\
& \text { subject to } \int_{0}^{\infty} Q_{t} d t=S_{0}, \quad Q_{r} \geq 0
\end{aligned}
$$

\subsection{Optimal $R \& D$}

We first consider the cartel's response, that is, the suboptimization problem in (1). Let $\bar{Q}(>0)$ solve $p(Q)=C$, and let $T_{3}(\leq \infty)$ denote the date at which the cartel would exhaust its stock if $T=\infty$. ( $T_{3}$ is the earliest date of invention for which the cartel is unconstrained. $T_{3}<\infty$ if the demand curve has a choke-off price.) Let $\mu(T)$ denote the multiplier associated with the resource constraint in (1). Routine control theoretic arguments can then be used to establish that there exists a date $T_{1}$ (with $T_{3}>T_{1}>0$ ) and, for each $T$ there is a date $\tilde{T}$ (with $\left.T_{3}>\tilde{T}>T_{1}\right)$, such that:

$$
\begin{aligned}
& m\left(\tilde{Q}_{t}(T)\right)=\mu(T) e^{r t} \quad \text { for } 0 \leq t<T^{*}, \\
& \text { where } T^{*}=\min \left\{\max \left\{T_{1}, T\right\}, T_{3}\right\} \\
& \left(T^{*}=\min \left\{T, T_{3}\right\} \text { if } m(\bar{Q})<\mu(T) e^{\left.r \min \left\{T, T_{3}\right\}\right) ;}\right. \\
& \tilde{Q}_{t}(T)=\bar{Q} \quad \text { for } T^{*} \leq t \leq \tilde{T} \text {, with } \mu(T) e^{r \tilde{T}}=C ;^{4} \text { and } \\
& \tilde{Q}_{t}(T)=0 \quad \text { for } t>\tilde{T} \\
& (\tilde{T} \text { is the date of resource exhaustion.) }
\end{aligned}
$$

In words, if $T \leq T_{1}$ marginal revenue rises at the rate $r$ until $T_{1}$, at which date price equals $C$, after which it remains at $C$. If $T_{1}<T<T_{3}$ marginal revenue rises at the rate $r$ until $T$, at which date price fails discontinuously to $C$. (At $T$ there may or may not be any remaining reserves. See below.) If $T \geq T_{3}$, marginal

${ }^{4}$ We shall note presently that there exists a date $T_{2}\left(T_{1}<T_{2}<T_{3}\right)$ such that if $T \geq T_{2}$, then $\tilde{T}=T^{*} ;$ that is, if $T \geq T_{2}$, then the cartel does not pursue the extraction phase characterized by (3). 
revenue rises at the rate $r$ until $T_{3}$ at which date reserves are exhausted, and the market is inoperative during $\left(T_{3}, T\right)$.

Hoel [4] has analyzed the cartel's response to our problem for the case $T=0$. He has shown that if $-f^{\prime}(p) p / f(p)>1$ at $p=C$, there exists $\hat{S}$ such that if $S_{0}>\hat{S}$, then $T_{1}>0$ and $S_{T_{1}}>0$. For concreteness we shall assume that this is so. ${ }^{3}$ It is then obvious that the cartel's response is invariant to $T$ if $0 \leq T \leq T_{1}$. From this we may conclude that the importing nation will choose $T \geq \widetilde{T}_{1}$.

Since $S_{T_{1}}>0$, it follows by continuity of the state variable that $S_{T}>0$ if $T$ is slightly larger than $T_{1}$. Condition (3) implies then that for $T$ slightly larger than $T$.

$$
\mu(T) e^{r T}=C e^{-r S_{T} / Q},
$$

and (2) implies that

$$
S_{T}=S_{0}-\int_{0}^{T} m^{-1}\left(\mu(T) e^{r t}\right) d t .
$$

From (5) and (6) we can therefore conclude that

$$
\int_{0}^{T}{ }^{m^{-1}}\left(\mu(T) e^{r t}\right) d t+(\bar{Q} / r) \log (C / \mu(T))=S_{0}+\bar{Q} T .
$$

Differentiating (7) with respect to $T$, and writing $q(\cdot) \equiv m^{-1}(\cdot)$, we have

$$
\tilde{Q}_{T}^{-}(T)+\int_{0}^{T} \mu^{\prime}(T) e^{r t} q^{\prime}\left(\mu(T) e^{r t}\right) d t-(\bar{Q} / r) \mu^{\prime}(T) / \mu(T)=\bar{Q},
$$

where $\tilde{Q}_{T}^{-}(T) \equiv \lim _{t \rightarrow r-0} \tilde{Q}_{t}(T)$. But $\tilde{Q}_{T}^{-}(T)<\bar{Q}$, from (2) and (3). Therefore (8) implies that $\mu^{\prime}(T)<0$. Fron (2) it follows that $d \tilde{Q}_{t}(T) / d T>0$, and therefore that $d S_{T} / d T<0$. In fact, from (5) and (6) it follows that there exists a negative number, $-\delta$, such that

$$
-\delta>d S_{T} / d T>-Q \text {. }
$$

Since (9) implies that $d S_{T} / d T$ is bounded away from zero, we can conclude that there exists a date $T_{2}$, such that $S_{T}=0$ if $T \geq T_{2}$, and $S_{T}>0$ if $T<T_{2}$. This means that $\tilde{T}=\min \left\{T, T_{3}\right\} \equiv T^{*}$ if $T \geq T_{2}$, and $T_{2}>\tilde{T}>T$ if $T<T_{2}$. Furthermore, $\tilde{T}$ is increasing in $T$ in the interval $\left(T_{1}, T_{2}\right){ }^{6}$

We have established the somewhat surprising result that $\mu(T)$-and hence the initial price $p\left(Q_{0}(T)\right.$ )-is decreasing in $T$, and $\tilde{Q}_{t}(T)$ is increasing in $T$ in the interval $\left(T_{1}, T_{2}\right)$. It is simple to check that $\mu(T)$, and hence $p\left(Q_{0}(T)\right)$, is increasing (and therefore $\tilde{Q}_{1}(T)$ is decreasing) in $T$ if $T_{3} \geq T>T_{2}$. (By defini-

${ }^{5}$ The remaining possibilities can similarly be analyzed, but we wish to avoid a complete taxonomy here.

${ }^{6}$ To see this, note that if $T<T_{2}$, then $\tilde{T}=T+S_{T} / \bar{Q}$. Thus $d \tilde{T} / d T=1+\left(d S_{T} / d T\right) / \bar{Q}>0$, on using (9).

Reproduced with permission of the copyright owner. Further reproduction prohibited without permission. 
programs" can be optimal precisely because they are a credible means of forcing the cartel to pursue a more favorable intertemporal pricing policy.

To confirm this, suppose that optimum $T \leq T_{3}$. Since we know that $T \geq T_{1}$, we may use (2) and (3) to re-express the importing country's objective as

$$
\underset{T \geq T_{1}}{\operatorname{maximize}}\left[\int_{0}^{T} V\left(\tilde{Q}_{t}(T)\right) e^{-r t} d t+V(\bar{Q}) e^{-r T} / r-X(T)\right]
$$

where $V(Q) \equiv U(Q)-p(Q)) Q$

Notice first that even if $\ell^{\prime \prime}(T)>0,(10)$ is not necessarily concave in $T$. However, on the assumption that optimum $T \in\left(T_{1}, T_{3}\right)$ and does not equal $T_{2}$, it must satisfy the social cost-benefit rule:

$$
\begin{aligned}
& \int_{0}^{T} V^{\prime}\left(Q_{r}(T)\right)\left[d \bar{Q}_{r}(T) / d T\right] e^{-r t} d t+\left[V\left(\tilde{Q}_{T}^{-}(T)\right)-V(\bar{Q})\right] e^{-r T} \\
& \quad=X^{\prime}(T){ }^{8}
\end{aligned}
$$

The first term on the left-hand side of (11) yields the effect of a delay in the date of R\&D completion on social surplus generated in the importing country before that date. We have seen that it is positive if $T_{1}<T<T_{2}$, and is negative if $T_{2}<T<T_{3}$. (For $T \geq T_{3}$ it is zero.) However, each additional moment's delay results in a loss in social benefits due to the fact that market price just before this date exceeds $C$ (i.e., $p\left(\tilde{Q}_{T}^{-}(T)\right)>C$ ). The second term on the left-hand side of (11) is negative, and measures this loss. The sum of these two effects must equal the R\&D expenditure saved because of this delay, which is the right-hand side of (11). In Figure 2 we have drawn the gross benefit function of the importing country (the first two terms in (10)). We have seen that its slope is negative for $T>T_{2}$. It is simple to confirm that its slope is negative if $T$ is slightly less than $T_{2}$. It follows that by suitably choosing $X(T)$, and therefore the right-hand side of (11), we can ensure that optimum $T$ is less than $T_{2}$, establishing the result we have emphasized above. But note that the gross benefit function is positively sloped in a neighborhood to the right of $T_{1}$. This implies that optimal $T$ is outside this neighborhood. What this means is that there is a precise sense in which one may have an invention too early. It pays the importing country to delay making the invention until sometime after $T_{1}$, not only because it saves on $R \& D$ costs but also, somewhat paradoxically, because it benefits from a more favorable pricing policy on the part of the cartel. One notes in particular that in this interval a delay in the completion date is beneficial to both parties.

${ }^{8}$ Expression (10) is not differentiable at $T_{1}, T_{2}$, and $T_{3}$, although right and left derivatives exist. If optimum $T$ exceeds $T_{3}$ and is finite, it must satisfy the cost-benefit rule:

$$
-[V(\bar{Q})-V(0)] e^{-r T}=X^{\prime}(T)
$$




\section{Consider the case where the cartel and the importing cointry move simulta-} neously. ${ }^{10}$ Suppose $T>T_{1}$. (We shall see that (Nash) equilibrium $T$ exceeds $T_{1}$.) Given $T$, it is simple to calculate the cartel's response: it is the solution of the sub-optimization problem of $(1)$. This yields $S_{\hat{T}}(T)$, the remaining reserves at $\hat{T}$. It remains to analyze the importing country's response. From the analysis presented in Section (2.2) we may infer that (Nash) equilibrium $T$ will not be less than $T_{1}$. If the cartel does commit itself to a sales policy during $[0, \hat{T}]$ the importing country cannot influence the cartel's extraction of its remaining reserves in this period, but it can from $\hat{T}$ onwards. It follows that if equilibrium $T \leq T_{3}$ the importing country's problem is:

$$
\underset{T \geq T_{1}}{\operatorname{maximize}}\left[\int_{\hat{T}}^{T} V\left(\tilde{Q}_{1}(T)\right) e^{-r t} d t+V(\bar{Q}) e^{-r T} / r-X(T)\right],
$$

subject to $S_{\hat{T}}$ being available at $\hat{T}$.

The solution of (12), assuming it to be unique, yields the reaction function of the importing country. Let $T_{n}$ be the Nash equilibrium date of invention. "It can be shown that if $T_{n}<(>) T_{2}$, then $T_{n}$ is less than (greater than) the optimum date of invention in the model of Section 2.2. But this means that if $T_{n}<T_{2}$, the cartel would prefer to follow rather than move simultaneously-or in other words, prefer not to bind itself to any contract for the period $(0, \hat{T})$. In this case the equilibrium outcome would be the same as the one in Section 2.2.

Let us now drop the hypothesis that the importing country has sole access to the R\&D technology. To begin with, continue to assume that the cartel's $\mathrm{R} \& \mathrm{D}$ technology is vastly inferior to its rivals', so that it does not enter the $R \& D$ race. In order to assess the incentives for developing the substitute product two broad categories of agents must be distinguished: resource users and R \& D firms. By the latter we mean firms that are not resource users themselves. Such a firm is indifferent to the cartel's current pricing policy, except insofar as it influences the size of remaining reserves at the date the firm's $R \& D$ program is completed-the value of the invention to the firm being smaller, presumably, the larger are remaining reserves. Resource users, on the other hand, do care about the cartel's current extraction policy, as expression (10) makes clear. In Section 2.2 we analyzed the incentives that a particular type of resource user (an importing country) has for developing a substitute product. Consider now by way of contrast the case where there is a patent race only among $\mathrm{R} \& \mathrm{D}$ firms, with the winner taking all. For concreteness, we may suppose that the cartel makes the first move and commits itself to an extraction policy, and that this is followed by $\mathrm{R} \& \mathrm{D}$ competition. If reserves are positive at the date the patent is awarded, the market at the date is one of duopoly. Let $Z\left(S_{T}\right)$ be the present value of profits to the patent winner at $T$ if $S_{T}$ denotes remaining reserves at $T$. Suppose that free-entry among $R \& D$ firms results in zero profit as an equilibrium condition.

${ }^{10}$ The analysis for the case where the cartel moves first can likewise be developed.

"It is clear that if $\hat{T}=0$ the present model reduces to the one in Section 2.2. 


$$
Z\left(S_{T}\right) e^{-r T}=X(T)
$$

It is natural to assume that $Z^{\prime}(S)<0$. This and (13) imply that, contrary to what is of ten thought, a high price for a resource today does not imply that the incentives among $\mathrm{R} \& \mathrm{D}$ firms to invent a substitute is high. $R \& D$ deterrence involves the cartel maintaining a high price for its resource. Indeed, it is a simple matter to confirm that equilibrium in this game involves a higher resource price than would have prevailed in a market where there is no threat of entry by $R \& D$ firms. But the welfare effects are ambiguous, since resource price after the invention is lower.

Now suppose that the cartel also has access to the R\&D technology, but continue to assume that no resource user can engage in $R \& D$. In this case it is easy to see that the cartel will pre-empt its rivals and win the patent. ${ }^{12}$ The reason is this. For any given level of remaining reserves the cartel's combined profits from resource sales and substitute production (were it to win the patent) exceeds the sum of the profits accruing to it from resource sales and to the patent winner from substitute production (were the cartel not to win the patent). It follows that given any level of remaining reserves the cartel makes positive profits at all $R \& D$ levels for which rivals earn zero profit.

If the cartel can engage in $\mathrm{R} \& \mathrm{D}$ it has two sets of controls to deter rivals: the resource price and $R \& D$ expenditure. One might conjecture that the cartel resorts less to the former if pre-emptive patenting is an option. It is a simple matter to confirm this intuition if demand is iso-elastic and the initial stock is "large." In such a situation a market in which the cartel can engage in $R \& D$ has prices lower at all dates prior to the date of invention. Invention and innovation both occur earlier than in the case where the cartel cannot compete in R\&D. Moreover, the dates of $R \& D$ completion and innovation do not coincide: there are "sleeping patents."

The argument establishing pre-emptive patenting on the part of the cartel does not hold if resource users also have access to the R \& D technology. The cartel's combined profits from resource sales and substitute production do not necessarily exceed the sum of benefits accruing to it from resource sales and the benefits to the patent winner if the winner is a resource user. In particular, the payoff to the resource user from making the invention depends not only on the size of remaining reserves at the date development is completed, but also on the cartel's pricing policy prior to this date.

\section{CONCLUSIONS}

Strategic considerations are clearly central to the design of $R \& D$ policies by resource importing countries and to the determination of extraction policies by

${ }^{12}$ The general argument is given in Dasgupta and Stiglitz [1].

Reproduced with permission of the copyright owner. Further reproduction prohibited without permission. 
resource cartels. Yet national energy studies rarely take them into account. In this article we have attempted to provide a framework for such an analysis. Strategic considerations may induce a resource user (e.g. an importing country) to complete the development of the substitute product at a date earlier than the date at which it intends to introduce it, even though this involves additional $\mathrm{R} \& \mathrm{D}$ expenditure. Concomitant with this are circumstances in which an importing country deliberately delays $R \& D$ completion, even if it could complete at an earlier date at no extra cost, because such a delay induces the cartel to lower its price at all dates prior to R \& D completion.

Similar paradoxical results obtain if the resource cartel behaves strategically. The threat of the development of a substitute by $R \& D$ firms induces the cartel to raise its price and, if the cartel also has access to a similar $R \& D$ technology, it pre-empts its rivals, thereby maintaining its monopoly position. This pre-emption argument, however, does not carry over if resource users compete in the R \& D race.

London School of Economics,

University of California, Berkeley,

and

Princeton University'

Mamuscript received May, 1982; final revision received November, 1982.

\section{REFERENCES}

[1] Dasgupta, P., AND J. Stiglitz: "Uncertainty, Market Struclure and the Speed of R\&D," Bell Journal of Economics, 11(1980), 1-28.

[2] Dasgupta, P., R. Gilibert, and J. Stiglitz: "Invention and Innovation under Alternative Market Structures: The Case of Natural Resources," Review of Economic Studies, 49(1982), $567-582$.

[3] Gailuist, N., T. Lewwis, and R. Ware: "Strategic Timing and Pricing of the Substitute in the Carlelized Resource Market," mimeo, Department of Economics, University of British Columbia, 1982.

[4] Hotz. M.: "Resource Extraction, Substitute Production and Monopoly," Journal of Economic Theory, 19(1978), 28-37.

[5] Mansfinid, E., M. Schiwartz, and S. Wagner: "Imitation Costs and Patents: An Empirical Study," Economic Journal, 91(1981), 907-918.

[6] National. Researcu Council: Energy' Modelling for an Uncertain Future, Supporting Paper 2 of Study of Nuclear and Alternative Energy, National Acadeny of Sciences, Washington, D.C., 1978. 